\title{
Improved Micropropagation of Plantlets from Nodal Explants of Anchote (Coccinia abyssinica)—A Calcium- and Protein-rich Tuber
}

\author{
Jane Kahia ${ }^{1}$ \\ World Agroforestry Centre (ICRAF), Cote d' Ivoire Country Program \\ Cocody Mermoz, Abidjan, Côte d'Ivoire
}

Peter Njenga

Jomo Kenyatta University of Agriculture and Technology, P.O. Box 6200000200, Nairobi, Kenya

\author{
Margaret Kirika \\ Institute of Water and Wetland Research, Radboud University, \\ Heijendaalseweg 135, 6525 AJ Nijmegen, The Netherlands
}

Additional index words. Coccinia abyssinica, phytohormones, nodal explants, micropropagation

\begin{abstract}
The effect of phytohormones on breaking of dormancy of axillary buds in anchote and their subsequent shoot proliferation were examined. Anchote is an annual trailing endemic plant with high calcium content grown for its edible tuberous roots in Ethiopia. Nodal explants harvested from the greenhouse were sterilized using various concentrations of a commercial bleach (JIK) which contains $3.85 \%$ sodium hypochlorite $(\mathrm{NaOCl})$ and time duration. The highest $(85 \%)$ clean explants were obtained when $5 \%$ JIK was used for 15 minutes. The explants were cultured on Murashige and Skoog (MS) medium supplemented with various concentrations of benzylaminopurine (BAP), kinetin, and thidiazuron (TDZ). The highest frequency of microshoot induction (84\%) and mean number of microshoots (3.4) were recorded from explants cultured on medium supplemented with TDZ $0.025 \mu M$. Hyperhydrated shoots were observed on media supplemented with high concentrations of BAP and kinetin but interestingly not on TDZ media. Induction of roots was highest $(86 \% ; 4.6$ roots per shoot) when shoots were transferred to half strength $M S$ medium containing $0.5 \mu M \alpha$-naphthalene acetic acid (NAA) after 12 days. A survival rate of $83 \%$ was recorded in the greenhouse and the plantlets appeared to be morphologically normal. This is the first report on use of TDZ for in vitro propagation of anchote.
\end{abstract}

Anchote [Coccinia abyssinica (Lam.) Cogn.] is an annual trailing endemic plant with high calcium content grown for its edible tuberous roots in Ethiopia. It belongs to family Cucurbitaceae and is a major potential root and tuber plant produced in west Oromia (East Wollega, Ethiopia). The plant seems to have its center of origin and diversity in the western and southwestern parts of Ethiopia (Edwards, 1991). It is used as food (mainly tuber roots) and medicine for human in Ethiopia. The plant plays significant contributions toward food security, income generation, and provision of food energy in Ethiopia. It is also used as animal

\footnotetext{
Received for publication 3 Dec. 2015. Accepted for publication $10 \mathrm{Feb} .2016$.

We acknowledge the African Union for the financial support to carry out the study. Special thanks to the management and the staff of the Institute of Biotechnology Research at Jomo Kenyatta University of Agriculture and Technology for their technical support.

${ }^{1}$ Corresponding author. E-mail: j.kahia@cgiar.org.
}

much as they would want to scale-up its production. There is therefore need to explore alternative propagation methods. Micropropagation is advantageous over traditional propagation, as it can be used to provide a sufficient number of plantlets for planting from a stock plant which does not produce seeds or respond well to conventional propagation methods. In addition, small pieces of tissue are required for initiating cultures as compared with conventional stem cuttings and tuberous root slips. Moreover, plant regeneration from cells, tissues, and organ cultures is a prerequisite for the application of plant biotechnology for genetic improvement. Bekele et al. (2013), and Yambo and Feyissa (2013) have reported micropropgation of anchote using in vitro germinated seedlings and seedling growing in the greenhouse and BAP and kinetin. Based on review of available literature, there are no reports on the use of nodal explants harvested from plants raised from C. abyssinica tubers. On the other hand, the successful application of TDZ for in vitro propagation of anchote has not been reported. The aim of the study was to evaluate the effect of different phytohormones on in vitro propagation of anchote.

\section{Materials and Methods}

Anchote (C. abyssinica) tubers were collected from western Ethiopia and transported to Kenya where they were planted at the Jomo Kenyatta University of Agriculture and Technology shade house. The substrate used to grow the tubers was top soil mixed with cattle manure $(1: 1)$. The covering in the shade house was tilde net allowing 50\% light. Nodal explants were harvested after 2 months and these were used for all the experiments. The tissue culture experiments were carried out from Jan. to May 2014.

Media preparation. Nodal explants were cultured on MS medium, Murashige and Skoog (1962) basal salts supplemented with $3 \%(\mathrm{w} / \mathrm{v})$ sucrose, BAP, and kinetin evaluated at $0,0.1,0.2,0.3,0.5,1.5,2.5,5,10,20$, and $40 \mu \mathrm{M}$ and TDZ evaluated at $0,0.01$. $0.025,0.05,0.1,0.5,1$, and $1.5 \mu \mathrm{M}$ in separate experiments. Rooting of the microshoots was evaluated using half-strength MS media supplemented with $2 \%(\mathrm{w} / \mathrm{v})$ sucrose, indole-3-butyric acid (IBA), and NAA evaluated at $0,0.1,0.2,0.3,0.5$, and $1.2 \mu \mathrm{M}$. The $\mathrm{pH}$ was adjusted to 5.8 using $0.1 \mathrm{M} \mathrm{HCl}$ or $0.1 \mathrm{M} \mathrm{NaOH}$, and the media was gelled with $0.3 \%$ phytagel. The media was dispensed in $20 \mathrm{~mL}$ aliquots into culture vessels and then autoclaved at $1.06 \mathrm{~kg} \cdot \mathrm{cm}^{-2}$ and $121^{\circ} \mathrm{C}$ for $15 \mathrm{~min}$.

Sterilization of explants. The nodal explants were excised using sterile surgical blade and placed in a beaker containing tap water. Surface detritus were removed by cleaning with liquid soap in the laboratory under running tap water. Explants were then transferred to the laminar flow cabinet, immersed in $70 \%(\mathrm{v} / \mathrm{v})$ ethanol for $30 \mathrm{~s}$ and 
rinsed twice with sterile distilled water. Thereafter, they were subjected to sterilization using two concentrations ( $5 \%$ and $10 \%$ ) of a commercial bleach (JIK) which contains $3.85 \% \mathrm{NaOCl}$ for 5,10 , and $15 \mathrm{~min}$. They were then rinsed four times in sterile distilled water.

Inoculation and incubation. The sterilized nodal explants were trimmed to remove the parts damaged by the bleach and inoculated on the microshoot regeneration media under evaluation. On the other hand, the regenerated microshoots were excised and cultured on the rooting media under evaluation. The cultures were incubated in a growth room maintained at $25 \pm 2{ }^{\circ} \mathrm{C}$ and 16-h photoperiod with an irradiance of 62.2 $\mu \mathrm{mol} \cdot \mathrm{m}^{-2} \cdot \mathrm{s}^{-1}$ provided by cool white fluorescent tubes.

The experiments were laid out in completely randomized design with each treatment repeated at least two times. Twenty replicates per treatment were used for all the experiments. For the sterilization experiment, percent clean explants were recorded. For induction of microshoots, percentage of nodal explants that produced shoots, the number of microshoots, and their lengths were recorded after 3 weeks. For the rooting experiment, the mean number of microshoots with roots, numbers of roots, and their lengths were evaluated. All the data were subjected to one-way analysis of variance and differences between means were determined by a Duncan's test. The tests were considered as significant with $P<0.05$.

Acclimatization. The rooted plantlets (20/treatment) were taken out from the culture vessels and washed off the traces of agar. They were then taken to the shade house where they were treated with green copper fungicide for $20 \mathrm{~min}$. The covering in the shade house was tilde net allowing $50 \%$ light. They were planted in pots containing different potting substrate to acclimatize. The substrates evaluated were top soil:cattle manure $(1: 1 \mathrm{v} / \mathrm{v})$, soil:peat fertilizer:ADP $(3: 1: 1 \mathrm{v} / \mathrm{v})$, top soil:river sand:cattle manure $(3: 1: 2 \mathrm{v} / \mathrm{v})$, and top soil with no other additives. The plantlets were covered with polythene bags to introduce high relative humidity. After 2 weeks, holes were punctured on the polythene bag to reduce the humidity and this was done on a weekly basis for 4 weeks after which the bag was eventually removed. The plantlets were watered every week with tap water using a hand-operated sprayer.

\section{Results}

Effect of different JIK concentrations and duration on elimination of surface contamination from anchote nodal explants. Sterilizing the nodal explants with $5 \%$ JIK for $15 \mathrm{~min}$ resulted in the highest $(85 \%)$ clean explants (Table 1). It was also observed that the higher concentration (10\%) of JIK lead to death of the explants.
Table 1. Effect of various concentrations of JIK and time duration on sterilization of anchote nodal explants.

\begin{tabular}{lccccc}
\hline $\begin{array}{l}\text { Concn of } \\
\text { JIK }(\% \mathrm{v} / \mathrm{v})\end{array}$ & Time $(\mathrm{min})$ & $\begin{array}{c}\text { Dead } \\
\text { explant }(\%)\end{array}$ & $\begin{array}{c}\text { Fungal } \\
\text { contamination }(\%)\end{array}$ & $\begin{array}{c}\text { Bacterial } \\
\text { contamination (\%) }\end{array}$ & $\begin{array}{c}\text { Clean } \\
\text { explants }(\%)\end{array}$ \\
\hline 5 & 5 & $4.0 \pm 0.6 \mathrm{e}$ & $18.2 \pm 0.8 \mathrm{~b}$ & $16.5 \pm 2 \mathrm{~b}$ & $63.9 \pm 1.0 \mathrm{~d}$ \\
5 & 10 & $6.8 \pm 0.3 \mathrm{c}$ & $8.5 \pm 0.6 \mathrm{c}$ & $7.7 \pm 0.5 \mathrm{c}$ & $76.7 \pm 0.4 \mathrm{~b}$ \\
5 & 15 & $9.3 \pm 0.6 \mathrm{c}$ & $3.2 \pm 0.3 \mathrm{~d}$ & $3.0 \pm 0.3 \mathrm{~d}$ & $84.5 \pm 0.5 \mathrm{a}$ \\
10 & 5 & $21.5 \pm 1 \mathrm{~b}$ & $15.9 \pm 2 \mathrm{c}$ & $10.9 \pm 2 \mathrm{c}$ & $67.3 \pm 0.7 \mathrm{c}$ \\
10 & 10 & $23.7 \pm 1 \mathrm{~b}$ & $3.1 \pm 0.2 \mathrm{~d}$ & $3.1 \pm 0.9 \mathrm{~d}$ & $72.4 \pm 1.0 \mathrm{c}$ \\
10 & 15 & $32.2 \pm 1 \mathrm{a}$ & $2 \pm 0.2 \mathrm{~d}$ & $0 \pm 0 \mathrm{e}$ & $68.8 \pm 0.8 \mathrm{c}$ \\
\hline
\end{tabular}

Values represent means \pm SE. Means within a column followed by different letters are significantly different at $P<0.05$.

Table 2. Effect of various concentrations of TDZ on microshoot formation.

\begin{tabular}{lcccc}
\hline TDZ concn $(\mu \mathrm{M})$ & \% Response & $\begin{array}{c}\text { Mean no. of } \\
\text { shoots/explant }\end{array}$ & $\begin{array}{c}\text { Mean shoot length } \\
(\mathrm{cm}) / \text { explant }\end{array}$ & $\begin{array}{c}\text { Mean no. of } \\
\text { leaves/explant }\end{array}$ \\
\hline 0.01 & $75 \pm 0.7 \mathrm{~b}$ & $2.5 \pm 0.2 \mathrm{~d}$ & $1.56 \pm 0.4 \mathrm{a}$ & $3 \pm 0.1 \mathrm{e}$ \\
0.025 & $84 \pm 0.4 \mathrm{a}$ & $3.4 \pm 0.1 \mathrm{a}$ & $1.53 \pm 0.4 \mathrm{~b}$ & $6 \pm 0.7 \mathrm{c}$ \\
0.05 & $75 \pm 0.5 \mathrm{~b}$ & $3.20 \pm 0.3 \mathrm{~b}$ & $1.5 \pm 0.2 \mathrm{~b}$ & $8 \pm 0.6 \mathrm{a}$ \\
0.1 & $55 \pm 0.5 \mathrm{c}$ & $2.67 \pm 0.3 \mathrm{c}$ & $0.9 \pm 0.2 \mathrm{~d}$ & $7 \pm 0.1 \mathrm{~b}$ \\
0.5 & $25 \pm 0.2 \mathrm{~d}$ & $2.0 \pm 1 \mathrm{~d}$ & $0.5 \pm 0.1 \mathrm{e}$ & $5 \pm 0.2 \mathrm{~d}$ \\
1 & $17 \pm 0.4 \mathrm{e}$ & $1.2 \pm 0.4 \mathrm{e}$ & $0.4 \pm 0.3 \mathrm{e}$ & Callusing \\
1.5 & $8 \pm 0.7 \mathrm{f}$ & $1.0 \pm 1 \mathrm{e}$ & $0.3 \pm 0.5 \mathrm{e}$ & Callusing \\
\hline
\end{tabular}

$\mathrm{TDZ}=$ thidiazuron

Values represent means \pm SE. Means within a column followed by different letters are significantly different at $P<0.05$.

Effect of TDZ concentrations on microshoot formation. Inclusion of TDZ in the media had a significant $(P \leq 0.05)$ effect on microshoot formation. The media supplemented with TDZ $0.025 \mu \mathrm{M}$ produced the highest (84\%) number of microshoots formation, with the highest $(3.40 \pm 0.1)$ mean number of microshoots per explant (Table 2). Increasing the concentration of TDZ from 0.05 to $1.5 \mu \mathrm{M}$ resulted in decrease of the number of responsive culture and the mean number of microshoots. The highest TDZ concentration ( 1 and $1.5 \mu \mathrm{M})$ leads to formation of callus (Fig. 1) and produced the lowest (1.2 and 1, respectively) mean number of microshoots. There were shoots formed on media without hormones (control).

Effect of BAP concentrations on microshoot formation. Inclusion of BAP in the media had a significant $(P \leq 0.05)$ effect on microshoot formation. The highest (85\%) microshoot formed were obtained on the medium supplemented with $0.5 \mu \mathrm{M}$ BAP (Table 3) and the lowest (27.5\%) on the medium supplemented with $40 \mu \mathrm{M}$ BAP. On the other hand, the highest $(3.40 \pm 0.5)$ mean number of shoots/explant and length $(3.20 \pm$ $0.2 \mathrm{~cm}$ ) were obtained on the medium supplemented with $2.5 \mu \mathrm{M}$ BAP while the lowest mean number $(1.40 \pm 1)$ were obtained with $40 \mu \mathrm{M}$ BAP. Increasing the concentration of BAP from 2.5 to $40 \mu \mathrm{M}$ led to a significant decrease in the number of responsive cultures. It was also observed that the higher concentrations of BAP ( $5 \mu \mathrm{M}$ and above) resulted in hyperhydrated shoots, callus formation, and yellowing of stem and leaves (Fig. 2). In contrast, the lower concentrations of BAP produced normal vigorous growing, green microshoots. There were shoots formed on media without hormones (control).

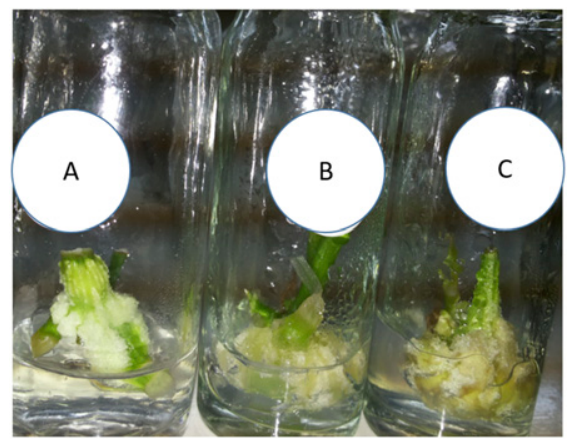

Fig. 1. Effects of thidiazuron at (A) $0.5 \mu \mathrm{M}$, (B) $1 \mu \mathrm{M}$, and $(\mathbf{C}) 1.5 \mu \mathrm{M}$ on microshoot regeneration (see callus formation at the base).

Effect of different Kinetin concentrations on microshoot formation. Inclusion of kinetin in the media had a significant $(P \leq 0.05)$ effect on microshoot formation. The media supplemented with $2.5 \mu \mathrm{M}$ kinetin produced the highest $(72 \%)$ responsive cultures and the highest $(2.60 \pm 0.7)$ mean number microshoot per explant (Table 4$)$. The lowest $(1.30 \pm 0.1)$ mean number of microshoots was obtained on media supplemented with $0.1 \mu \mathrm{M}$ kinetin. There were shoots formed on media without hormones (control). Increasing the concentration of kinetin from 5 to $40 \mu \mathrm{M}$ significantly reduced the mean number of responsive cultures. It was also observed that nodal explants cultured on media supplemented with high kinetin concentration led to formation of microshoots that were hyperhydrated and yellow in color.

Effect of NAA concentrations on in vitro rooting of anchote microshoots. Inclusion of NAA in the media had a significant $(P \leq$ 0.05 ) effect on root formation. Microshoots cultured on media supplemented with $0.5 \mu \mathrm{M}$ 
Table 3. Effects various BAP concentrations on microshoot formation.

\begin{tabular}{lrcrr}
\hline BAP concn $(\mu \mathrm{M})$ & \% Response & $\begin{array}{c}\text { Mean no. of } \\
\text { shoots/explant }\end{array}$ & $\begin{array}{c}\text { Mean shoot length } \\
(\mathrm{cm}) / \text { explant }\end{array}$ & $\begin{array}{c}\text { Mean no. of } \\
\text { leaves/explant }\end{array}$ \\
\hline 0 & $40 \pm 0.2 \mathrm{e}$ & $1.0 \pm 0.6 \mathrm{df}$ & $1.54 \pm 0.3 \mathrm{c}$ & $1.5 \pm 1 \mathrm{f}$ \\
0.1 & $47 \pm 0.9 \mathrm{f}$ & $1.2 \pm 0.1 \mathrm{~d}$ & $1.56 \pm 0.1 \mathrm{c}$ & $3.2 \pm 0.4 \mathrm{e}$ \\
0.2 & $65.5 \pm 0.5 \mathrm{~d}$ & $1.6 \pm 0.5 \mathrm{~cd}$ & $1.71 \pm 0.2 \mathrm{c}$ & $3.4 \pm 0.9 \mathrm{e}$ \\
0.3 & $80 \pm 0.3 \mathrm{~b}$ & $1.9 \pm 0.2 \mathrm{c}$ & $1.90 \pm 0.2 \mathrm{c}$ & $4.2 \pm 0.7 \mathrm{~d}$ \\
0.5 & $85 \pm 0.5 \mathrm{a}$ & $2.2 \pm 0.1 \mathrm{bc}$ & $2.1 \pm 0.4 \mathrm{c}$ & $5.5 \pm 0.8 \mathrm{c}$ \\
1.5 & $80 \pm 0.7 \mathrm{~b}$ & $2.5 \pm 0.4 \mathrm{~b}$ & $2.6 \pm 0.1 \mathrm{~b}$ & $6.20 \pm 0.8 \mathrm{~b}$ \\
2.5 & $75 \pm 0.1 \mathrm{c}$ & $3.4 \pm 0.5 \mathrm{a}$ & $3.2 \pm 0.2 \mathrm{a}$ & $8.5 \pm 0.9 \mathrm{a}$ \\
5 & $55 \pm 0.4 \mathrm{e}$ & $2.0 \pm 0.3 \mathrm{c}$ & $2.5 \pm 0.2 \mathrm{~b}$ & $6.8 \pm 0.5 \mathrm{~b}$ \\
10 & $45 \pm 0.5 \mathrm{f}$ & $1.8 \pm 0.7 \mathrm{c}$ & $1.8 \pm 0.2 \mathrm{c}$ & $5.67 \pm 0.6 \mathrm{bc}$ \\
20 & $35 \pm 0.9 \mathrm{~g}$ & $1.4 \pm 0.2 \mathrm{~d}$ & $1.70 \pm 0.4 \mathrm{c}$ & $5.65 \pm 0.3 \mathrm{bc}$ \\
40 & $27.5 \pm 1 \mathrm{~h}$ & $1.2 \pm 0.8 \mathrm{~d}$ & $1.52 \pm 0.2 \mathrm{c}$ & $5.52 \pm 0.5 \mathrm{c}$ \\
\hline
\end{tabular}

BAP $=$ benzylaminopurine.

Values represent means \pm SE. Means within a column followed by different letters are significantly different at $P<0.05$.
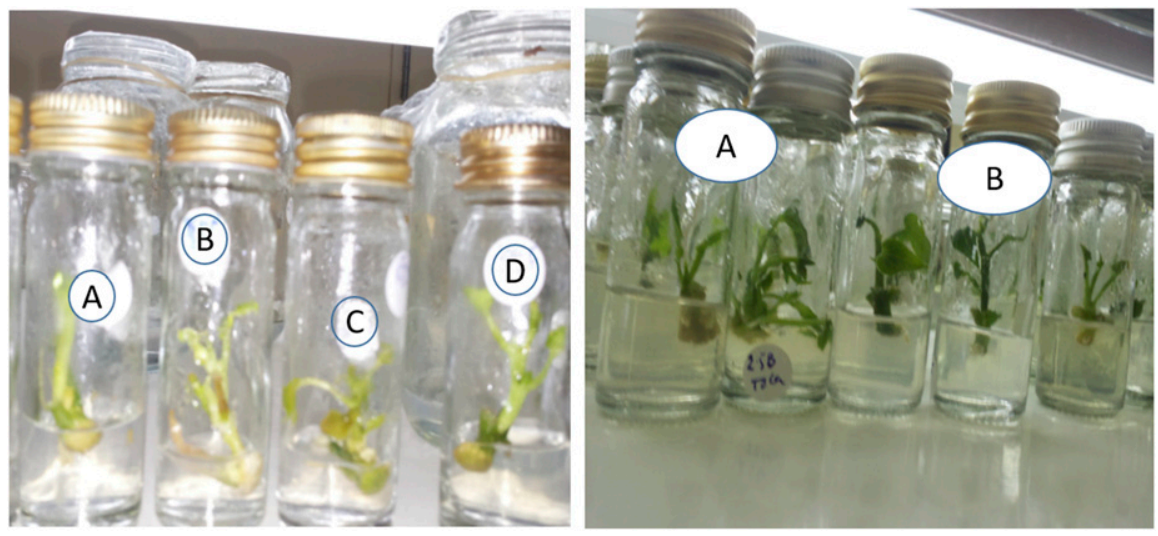

Fig. 2. Effects of benzylaminopurine concentrations on shooting: with high concentrations (note the hyperhydrated shoots and yellowing of stems) on the left (A-D) and low concentrations on the right (A) $2.5 \mu \mathrm{M}$ and (B) $0.5 \mu \mathrm{M}$ (normal shoots).

Table 4. Effect of various concentrations of kinetin on microshoot regeneration from anchote nodal explants.

\begin{tabular}{llcc}
\hline Kinetin concn $(\mu \mathrm{M})$ & \% Response & $\begin{array}{c}\text { Mean no. of } \\
\text { shoots/explant }\end{array}$ & $\begin{array}{c}\text { Mean shoot length } \\
(\mathrm{cm}) / \text { explant }\end{array}$ \\
\hline 0 & $42 \pm 0.3 \mathrm{fe}$ & $1.20 \pm 0.2 \mathrm{c}$ & $1.54 \pm 0.3 \mathrm{c}$ \\
0.1 & $45 \pm 0.5 \mathrm{e}$ & $1.30 \pm 0.1 \mathrm{c}$ & $1.56 \pm 0.4 \mathrm{c}$ \\
0.2 & $49 \pm 0.2 \mathrm{ed}$ & $1.42 \pm 0.8 \mathrm{bc}$ & $1.57 \pm 0.5 \mathrm{c}$ \\
0.3 & $58 \pm 0.1 \mathrm{c}$ & $1.54 \pm 0.2 \mathrm{~b}$ & $1.70 \pm 0.50 \mathrm{c}$ \\
0.5 & $65 \pm 0.2 \mathrm{~b}$ & $1.80 \pm 0.4 \mathrm{~b}$ & $2.76 \pm 0.8 \mathrm{a}$ \\
1 & $67 \pm 0.3 \mathrm{~b}$ & $1.94 \pm 1 \mathrm{~b}$ & $2.70 \pm 0.2 \mathrm{ab}$ \\
2.5 & $72 \pm 0.2 \mathrm{a}$ & $2.6 \pm 0.7 \mathrm{a}$ & $2.4 \pm 0.4 \mathrm{~b}$ \\
5 & $48 \pm 0.9 \mathrm{c}$ & $2.0 \pm 0.5 \mathrm{ab}$ & $2.20 \pm 0.5 \mathrm{~b}$ \\
10 & $39 \pm 0.5 \mathrm{f}$ & $1.5 \pm 0.9 \mathrm{bc}$ & $1.8 \pm 0.3 \mathrm{c}$ \\
20 & $21 \pm 0.9 \mathrm{e}$ & $1.3 \pm 0.3 \mathrm{c}$ & $1.78 \pm 0.4 \mathrm{c}$ \\
40 & $19 \pm 0.4 \mathrm{e}$ & $1.0 \pm 0.6 \mathrm{a}$ & $1.7 \pm 0.8 \mathrm{c}$ \\
\hline
\end{tabular}

Values represent means \pm SE. Means within a column followed by different letters are significantly different at $P<0.05$.

Table 5. Effects of various concentration of NAA on rooting of anchote microshoots.

\begin{tabular}{lccc}
\hline NAA concn $(\mu \mathrm{M})$ & \% Root response/explant & $\begin{array}{c}\text { Mean no. of } \\
\text { roots/explant }\end{array}$ & $\begin{array}{c}\text { Mean root length } \\
(\mathrm{cm}) / \text { explant }\end{array}$ \\
\hline 0 & $40 \pm 0.5 \mathrm{~g}$ & $2.1 \pm 1 \mathrm{~d}$ & $2.5 \pm 0.6 \mathrm{a}$ \\
0.1 & $55 \pm 0.3 \mathrm{f}$ & $2.5 \pm 0.2 \mathrm{~d}$ & $2.4 \pm 0.8 \mathrm{a}$ \\
0.2 & $65 \pm 0.2 \mathrm{e}$ & $2.7 \pm 0.2 \mathrm{~d}$ & $2.1 \pm 0.6 \mathrm{ab}$ \\
0.3 & $70 \pm 0.3 \mathrm{~d}$ & $3.3 \pm 0.4 \mathrm{c}$ & $1.6 \pm 0.7 \mathrm{~b}$ \\
0.5 & $86 \pm 0.3 \mathrm{a}$ & $4.6 \pm 0.6 \mathrm{~b}$ & $1.3 \pm 0.5 \mathrm{~b}$ \\
1 & $80 \pm 0.2 \mathrm{~b}$ & $5.5 \pm 0.5 \mathrm{a}$ & $1.20 \pm 0.6 \mathrm{~b}$ \\
2 & $76 \pm 0.7 \mathrm{c}$ & $5.7 \pm 0.6 \mathrm{a}$ & $1.0 \pm 0.7 \mathrm{~b}$ \\
\hline
\end{tabular}

NAA $=\alpha$-naphthalene acetic acid.

Values represent means \pm SE. Means within a column followed by different letters are significantly different at $P<0.05$.
NAA produced the highest $(86 \%)$ number of cultures with roots (Table 5). The highest concentrations of NAA ( 1 and $2 \mu \mathrm{M})$ produced the highest mean number of roots per explant $(5.50 \pm 0.5$ and $5.70 \pm 0.6$, respectively). On the other hand, the length of roots was observed to decrease with the increase in the concentration of NAA. Interestingly, the microshoots cultured on media without NAA produced the longest root length, although it was not significantly different from the length obtained with microshoots cultured on 0.1 and $0.2 \mu \mathrm{M}$ NAA.

Effect of IBA concentrations on in vitro rooting of anchote microshoots. Microshoots cultured on media supplemented with $0.5 \mu \mathrm{M}$ IBA produced the highest ( $84 \%$ ) number of cultures with roots and the highest $(3.40 \pm 0.8)$ mean number of roots (Table 6). Increasing the concentration of IBA increased the number and length of roots. Figure 3 shows the rooting of microshoots on media supplemented with IBA and NAA.

Acclimatization. The results of the survival rate of the micropropagated plantlets in different potting substrates in the shade house are shown in Table 7. Plantlets weaned in the top soil and cattle manure substrate had the highest $(83 \%)$ survival rate, although it was not significantly different from the rate obtained with top soil, river sand, and cattle manure and top soil, peat, and fertilizer (Table 7). The substrate containing top soil only produced the lowest $(66 \%)$ survival rate. The in vitro regenerated plantlets were morphologically identical to the mother plant and developed normally, and new shoots were observed after 2 weeks in the field.

\section{Discussion}

Explant contamination is a function of several plant and environmental related factors such as plant species, age, explant source, and prevailing weather condition. Previous workers on anchote used explants from in vitro-germinated seedlings (which did not require sterilization) and nodal explants derived from seedling growing in the greenhouse (Bekele et al., 2013; Yambo and Feyissa, 2013). During the current study, a higher percent number of clean explants were obtained than the numbers reported by Yambo and Feyissa (2013). A possible explanation for this difference could be the type of sterilant used and the skillfulness of the worker. It was also observed that nodal explants sterilized with concentrations higher than $5 \%$ died. The death of explants after exposure to higher concentrations of the sterilant could be due to scorching.

According to Capelle et al. (1983), TDZ directly promotes growth due to its own biological activities in a fashion similar to that of an $\mathrm{N}$-substituted cytokinin or it may induce the synthesis and accumulation of endogenous cytokinin. During the current 
study, the optimum TDZ concentration was found to be $0.025 \mu \mathrm{M}$. Increasing the concentration beyond the optimum led to significant reduction of the mean number of microshoots. This trend of decreased efficiency beyond the optimum TDZ concentration has been observed in somatic embryogenesis of Phalaenopsis aphrodite (Feng and Chen, 2014) and in micropropagation of lentils (Khawar et al., 2004). A possible explanation for this could be due to the fact that it is stable and biologically active at lower concentrations (Mok and Mok, 1987). The higher concentrations of TDZ were found to induce callus formation. Similar observations have been made in woody plant species, where low levels of TDZ have been known to induce the axillary shoot proliferation but higher levels may inhibit it and rather promote callus formation (Huetteman and Preece, 1993). This is the first report of the use of TDZ in tissue culture of anchote.

BAP was found to support microshoot formation in anchote and culturing nodal explants on media supplemented with 0.3 , 0.5 , and $1.5 \mu \mathrm{M}$ led to doubling of the number of cultures with normal microshoots when compared with the control. According to Yambo and Feyissa (2013), nodal explants cultured on media supplemented with more than $0.4 \mu \mathrm{M}$ BAP were observed to be hyperhydrated. This is contrary to the current study where normal vigorous growing shoots were observed on media supplemented with as high as $2.5 \mu \mathrm{M}$ BAP and hyperhydration was only observed when nodes were cultured on media supplemented with $5 \mu \mathrm{M}$ BAP or more. Hyperhydrated shoots did not root at all and died eventually when transferred to the rooting medium. A possible explanation for the observed hyperhydration in the current study could be due to the closure of the vessels used in the study. Alternatively, the high BAP concentrations could also have contributed since this phenomenon was only observed on nodes cultured on high BAP concentration. Incidentally, no hyperhydration was observed in all the TDZ concentrations evaluated.

Kinetin was found to be inferior to all the other cytokinins tested. Rout (2004) and Bertsouklis and Papafotiou (2011) made similar observations when working on Clitoria ternatea L. and Arbutus, respectively. During the current study, nodal explants cultured on media supplemented with $2.5 \mu \mathrm{M}$ kinetin produced $72 \%$ frequency of shoot multiplication. This is contrary to the work of Bekele et al. (2013), who reported very low $(23 \%, 27 \%$, and $44 \%)$ frequency of microshoot induction when 1,2 , and $3 \mu \mathrm{M}$ kinetin was used, respectively.

Auxins are important factors involved in rooting because they promote adventitious root formation in the vast majority of species (De Klerk, 2002). During the current study, NAA proved to be better rooting hormone for anchote microshoots compared with IBA. The results of the current study concur with those of Vuylsteke (1989), who reported that

Table 6. Effects of various concentration of IBA on rooting of anchote microshoots.

\begin{tabular}{lccc}
\hline IBA concn $(\mu \mathrm{M})$ & \% Root response/explants & $\begin{array}{l}\text { Mean no. of } \\
\text { root/explant }\end{array}$ & $\begin{array}{c}\text { Mean root length } \\
(\mathrm{cm}) / \text { explant }\end{array}$ \\
\hline 0.1 & $55 \pm 0.3 \mathrm{~d}$ & $2.4 \pm 1 \mathrm{bc}$ & $1.7 \pm 0.6 \mathrm{~b}$ \\
0.2 & $64 \pm 0.5 \mathrm{c}$ & $2.6 \pm 0.4 \mathrm{ab}$ & $1.9 \pm 0.7 \mathrm{~b}$ \\
0.3 & $75 \pm 0.1 \mathrm{~b}$ & $2.7 \pm 0.5 \mathrm{ab}$ & $2.1 \pm 0.4 \mathrm{ab}$ \\
0.5 & $84 \pm 1 \mathrm{a}$ & $3.4 \pm 0.8 \mathrm{a}$ & $2.3 \pm 0.3 \mathrm{a}$ \\
1 & $78 \pm 0.4 \mathrm{~b}$ & $3.2 \pm 0.6 \mathrm{a}$ & $2.4 \pm 0.9 \mathrm{a}$ \\
2 & $50 \pm 0.5 \mathrm{e}$ & $3 \pm 0.9 \mathrm{a}$ & $2.43 \pm 0.2 \mathrm{a}$ \\
\hline
\end{tabular}

IBA = indole-3-butyric acid.

Values represent means \pm SE. Means within a column followed by different letters are significantly different at $P<0.05$.
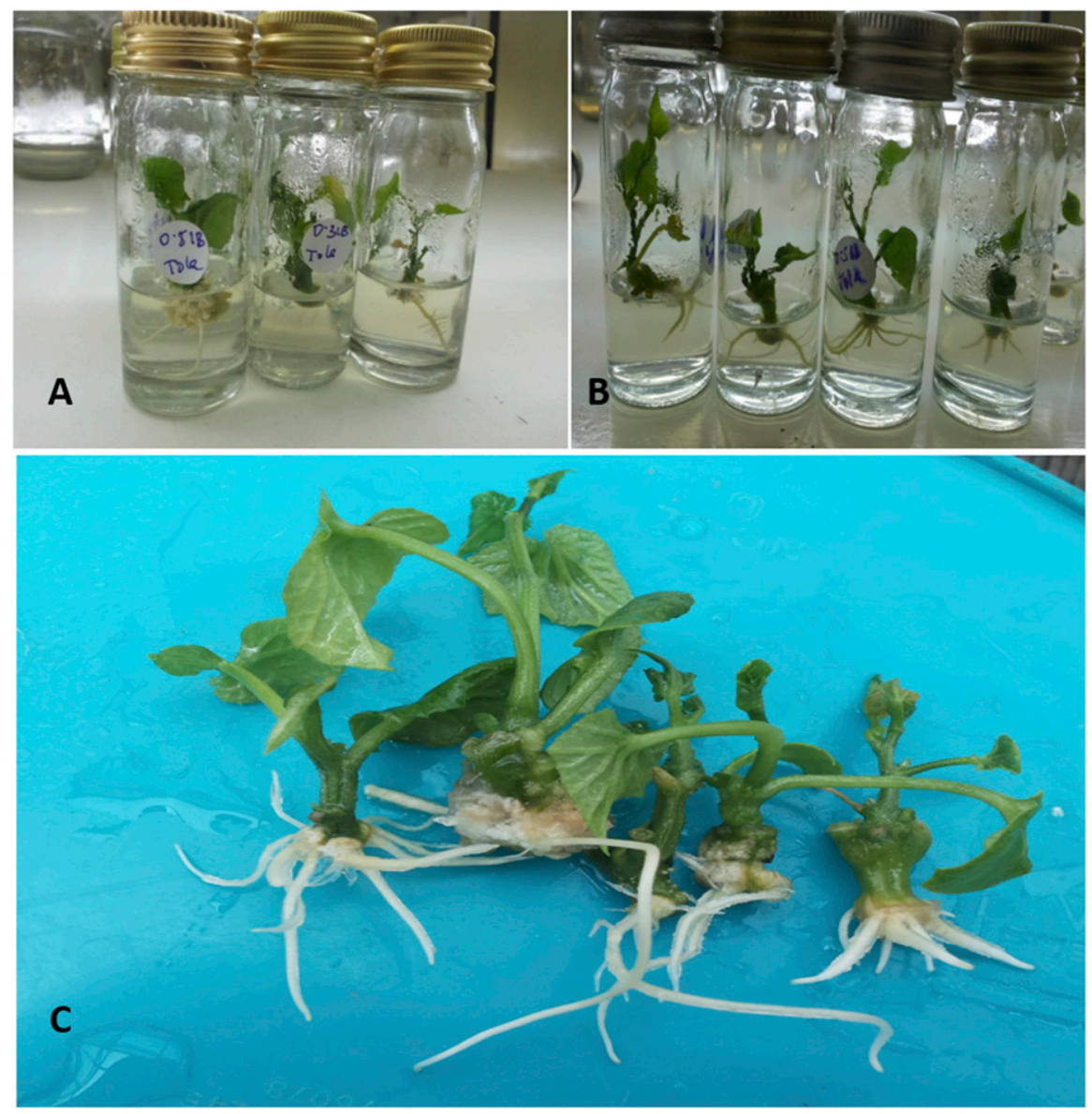

Fig. 3. In vitro roots regeneration with (A) $0.5 \mu \mathrm{M}$ indole-3-butyric acid, (B) $0.5 \mu \mathrm{M} \alpha$-naphthalene acetic acid, and $(\mathbf{C})$ plantlets ready for acclimatization.

NAA was more effective than IAA in banana. A possible explanation for this could be because the stability of the two auxins is different: IBA is slowly oxidized $(10 \%)$, while NAA is very stable (Dunlap et al., 1986). Another reason for the different effectiveness observed among the two auxins could be due to possible different affinities for auxin receptors, differences in uptake, transport, and metabolism (De Klerk et al., 1997).

The ultimate success of in vitro propagation lies in the successful establishment of plants in the soil (Saxena and Dhawan, 1999). During the current study, higher $(83 \%)$ survival rates were observed in the greenhouse compared with $68 \%$ reported by Yambo and Feyissa (2013). The high survival rates could be due to the rich potting substrates that we used. In fact, the plantlets weaned on potting substrate with only soil registered low survival rates. The regenerated plants did not show any variation in the morphology and growth when compared to the mother plant in the field (Fig. 4).

The present study demonstrates a simple and promising protocol for in vitro plantlet regeneration of anchote from nodal explants. The method described herein can go a long way in ensuring steady supply of anchote propagules to farmers throughout the year to meet the ever increasing demand of planting materials of this important indigenous species from Ethiopia. Moreover, the current studies facilitate development of a potential regeneration system using 
Table 7. Survival rates of in vitro regenerated anchote plantlets in the greenhouse.

\begin{tabular}{llcc}
\hline Treatments & Ratio & No. & \% Survival rate \\
\hline Soil + sand + manure & $3: 1: 2$ & 20 & $80.83 \pm 2 \mathrm{a}$ \\
Soil + manure & $1: 1$ & 20 & $83.33 \pm 1 \mathrm{a}$ \\
Soil + peat + fertilizer/ADP & $3: 1: 1$ & 20 & $82.7 \pm 0.9 \mathrm{a}$ \\
Soil only & $0: 1: 0$ & 20 & $65.83 \pm 3 \mathrm{~b}$ \\
\hline
\end{tabular}

Values represent means \pm SE. Means within a column followed by different letters are significantly different at $P<0.05$.
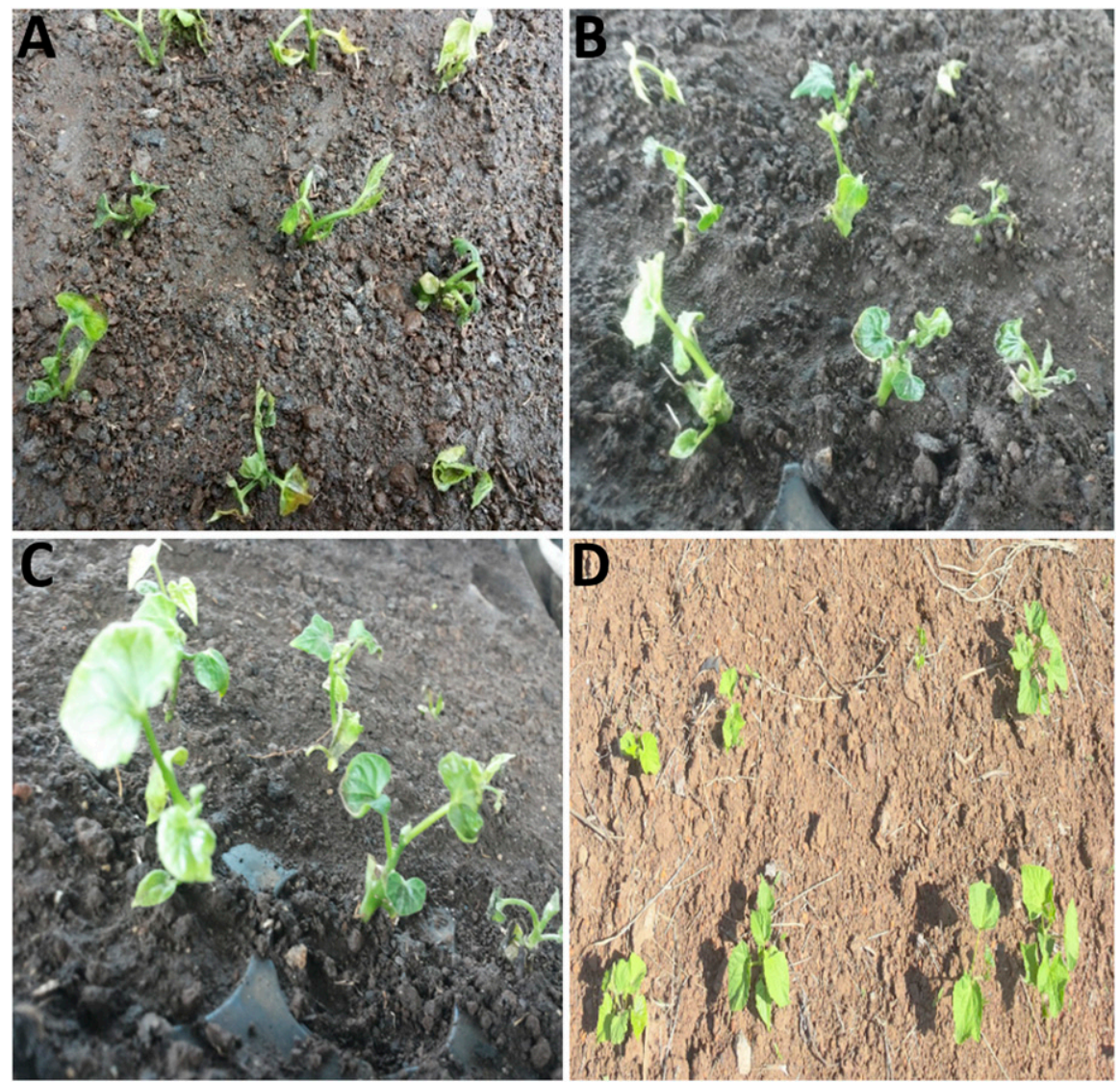

Fig. 4. Plantlets growing in the field after hardening; (A) 1 d; (B) 2 weeks, (C) 3 weeks, and (D) 4 weeks.

nodal explants as sterile starting material for either agrobacterium/biolistic mediated transformation.

\section{Literature Cited}

Bekele, F., B. Abera, and M. Getahun. 2013. In vitro propagation of Anchote (Coccinia abyssinica) (Lam.) Cogn.]. Afr. J. Plant Sci. 7(6): 253-264.

Bertsouklis, K.F. and M. Papafotiou. 2011. Effect of various cytokinins on micropropagation of Arbutus $\times$ andrachnoides Link. In XXVIII
International Horticultural Congress on Science and Horticulture for People (IHC2010): International Symposium on Micro. 923:213218.

Capelle, S.C., D.W.S. Mok, S.C. Kirchner, and M.C. Mok. 1983. Effects of thiadiazron on cytokinin autonomy and metabolism of N6(2- isopentyl) [8-14C] adenosine in callus tissue of Phaseolus lunatus L. Plant Physiol. 73:796-802.

De Klerk, G.J., B.J. Ter, and S. Marinova. 1997. Effectiveness of indoleacetic acid, indolebutyric acid and naphthaleneacetic acid during adventitious root formation in vitro in Malus “Jork 9". Plant Cell Tiss. Org. Cult. 49:39-44.

De Klerk, G.J. 2002. Rooting of microcuttings: Theory and practice. In Vitro Cell. Dev. Biol. Plant 38:415-422.

Dunlap, J.R., S. Kresovich, and R.E. McGee. 1986. The effect of salt concentration on auxin stability in culture media. Plant Physiol. 81:934-936.

Edwards, S. 1991. Crops with wild relatives in Ethiopia, p. 42-47. In: J.M.M. Engels, J.G. Hawkes, and W. Melaku (eds.). Plant genetic resources of Ethiopia. Cambridge University Press, Cambridge, UK.

Feng, J.H. and J.T. Chen. 2014. A novel in vitro protocol for inducing direct somatic embryogenesis in Phalaenopsis aphrodite without taking explants. Scientific World J. 2014:1-7.

Getahun, A. 1969. Developmental Anatomy of Seedlings and Tuber of Anchote, Coccinia abyssinica (Cucurbitaceae). Univ. of Florida, Gainesville, FL, PhD Diss.

Hora, A. 1995. Anchote: An endemic tuber crop. Artistic printing enterprise, Addis Ababa, Ethiopia.

Huetteman, C.A. and J.E. Preece. 1993. Thidiazuron: A potent cytokinin for woody plant tissue culture. Plant Cell Tissue Organ Cult. 33(2):105-119.

Jeffrey, C. 1995. Cucurbitaceae, Vol. 2, p. 52-55. In: S. Edwards, M. Tadesse, and I. Hedberg (eds.). Flora of Ethiopia and Eritrea. Natl. Herbarium, Addis Ababa Univ., and Uppsala Univ., Sweden.

Khawar, K.M., C. Sancak, S. Uranbey, and S. Ozcan. 2004. Effect of Thidiazuron on shoot regeneration from different explants of lentil (Lens culinaris Medik.) via organogenesis. Turk. J. Bot. 28:421-426.

Mengesha, D., D. Belew, W. Gebrasillasie, and W. Sori. 2012. Growth and yield performance of Anchote. Asian J. Plant Sci. 11:172-181.

Mok, D.W. and M.C. Mok. 1987. Metabolism of 14C-zeatin in phaseolus embryos occurrence of o-xylosyldihydrozeatin and its ribonucleoside. Plant Physiol. 84(3):T596-T599.

Murashige, T. and F. Skoog. 1962. A revised medium for rapid growth and bioassays with tobacco tissue cultures. Physiol. Plant. 15: 473-497.

Rout, G.R. 2004. Effect of cytokinins and auxins on micropropagation of Clitoria ternatea $\mathrm{L}$. Biol. Lett. 41(1):21-26.

Saxena, S. and B. Dhawan. 1999. Regeneration and large-scale propagation of bamboo (Dendrocalamusstrictus Nees) through somatic embryogenesis. Plant Cell Rep. 18:438-443.

Vuylsteke, D.R. 1989. Shoot-tip culture for the propagation, conservation and exchange of Musa germplasm. IBPGR, Rome.

Yambo, Y. and T. Feyissa. 2013. Micropropagation of anchote [Coccinia abyssinica (Lam.) Cogn.]: High calcium content tuber crop of Ethiopia. Afr. J. Agr. Res. 8(46):5915-5922. 